\title{
Foot pumps without graduated compression stockings for prevention of deep-vein thrombosis in total joint replacement: efficacy, safety and patient compliance
}

\author{
A comparative, prospective clinical trial
}

\author{
Rocco P. Pitto • Simon Young
}

Received: 17 December 2006 / Accepted: 25 December 2006 /Published online: 15 February 2007

(C) Springer-Verlag 2007

\begin{abstract}
Mechanical prophylaxis with foot pumps provides an interesting alternative to chemical agents in the prevention of thromboembolic disease following major orthopaedic surgical procedures. Recent studies have suggested that the simultaneous use of graduated compression stockings (GCS) may hinder the pneumatic compression effect of foot pumps. The hypothesis of this prospective study was that the use of foot pumps without GCS does not affect the efficacy of deepvein thrombosis (DVT) prophylaxis and improves patient compliance. A total of 846 consecutive patients admitted at a single institution undergoing total hip (THR) or knee replacement (TKR) were included in the study. The A-V Impulse System foot-pump unit (Orthofix Vascular Novamedix, Andover, UK) was used in all patients. Of these 846 patients, 46 discontinued the use of foot pumps, leaving 400 patients who received foot pumps in combination with GCS and 400 patients with foot pumps alone. Eleven patients of the stocking group $(2.7 \%)$ and nine patients of the nostocking group $(2.3 \%)$ developed postoperative symptomatic DVT $(p=0.07)$. DVT was more frequent in TKR $(10 / 364$; $2.7 \%)$ than in THR $(10 / 436 ; 2.3 \%)$. Non-fatal pulmonary embolism occurred in four of the 20 patients with symptomatic DVT, two patients each of the stocking and nostocking groups. The foot-pump discontinuation rate of patients treated with stockings was $7 \%$ versus $4 \%$ of the patients treated without stockings $(p<0.05)$. In conclusion, management of patients with foot pumps without GCS does
\end{abstract}

R. P. Pitto $(\bowtie) \cdot S$. Young

Department of Orthopaedic Surgery, Middlemore Hospital,

South Auckland Clinical School, University of Auckland,

Auckland, New Zealand

e-mail: r.pitto@auckland.ac.nz not reduce the efficacy of DVT prophylaxis after THR and TKR and improves patient compliance.

Résumé La prophylaxie des complications thrombo-emboliques par «pompage » pédieux est une alternative au traitement médical en chirurgie orthopédique. Une étude récente a montré que l'utilisation simultanée de bas à compression élastique et de compression pneumatique au niveau du pied peut cacher l'effet de cette dernière technique. L'hypothèse émise pour ce travail prospectif est la suivante, l'utilisation de pompes au niveau des pieds sans bas de contention élastique n'entraîne pas de complications thrombo-emboliques complémentaires. 846 patients ayant bénéficié d'une prothèse totale de hanche et du genou ont été inclus dans cette étude. Le système utilisé a été le AV impluse système foot pump units de Orthofix Vascular Novamedix, Andover. 46 patients ont bénéficié de la pompe en discontinue, 400 patients ont utilisé la pompe en combinaison avec les bas de contention et 400 patients la pompe uniquement.11 patients du groupe contention élastique $(2,7 \%)$ et 9 patients du groupe sans contention $(2,3 \%)$ ont présenté en post-opératoire une complication thrombo embolique $(p=0.07)$. Les complications de type thrombose veineuse profonde sont plus fréquentes dans la prothèse du genou (10 sur $364 ; 2.7 \%$ ) que dans la prothèse de hanche (10 sur $436 ; 2,3 \%) .4$ embolies pulmonaires n'ayant entraîné aucun décès sont survenues sur un groupe de 20 patients ayant présenté une thrombose veineuse symptomatique, 2 dans le groupe bas de contention et deux dans le groupe sans bas de contention. Le système de pompe, au niveau du pied en discontinue associé à des bas de contention élastiques a été de $7 \%$ en comparaison de patients traités sans contention $4 \%(p<0.05)$. En conclusion, l'utilisation d'un système de pompe au niveau du pied 
sans bas de contention élastique ne réduit pas l'efficacité de la prophylaxie du traitement des complications thromboemboliques de la prothèse totale de hanche dans la prothèse totale du genou et améliore le confort des patients.

\section{Introduction}

The routine use of prophylaxis against venous thromboembolic disease in total hip and knee replacement (THR, TKR) is recommended. Chemical prophylaxis, in particular in combination with low-molecular-weight heparin (LMWH), has been shown to significantly reduce the occurrence of deep-vein thrombosis (DVT); however, the untoward sideeffects, including haemorrhagic complications and heparininduced thrombocytopenia (HIT) syndrome, are frequent [2, $7-9,14,15,19]$. Mechanical prophylaxis with foot pumps provides an interesting alternative to chemical agents in the prevention of thromboembolic disease following major orthopaedic surgical procedures [11]. The International Consensus Statement Group reported that mechanical prophylaxis with foot pumps should be considered to be a "Grade A" recommendation for the prevention of DVT following THR [6]. Results from four independent randomised clinical trials have shown that mechanical prophylaxis with foot pumps in THR achieved equivalent - if not superior - results compared to chemical management [5, $11,13,16]$, but the tolerance of the device has been a problem for some patients $[3,12]$. The effective action of the foot pumps depends on various factors, including the frequency and pressure of the impulses and the dependency of the lower extremities $[1,4,10]$. It is not known whether the efficacy, safety and compliance of the foot pumps are enhanced by the simultaneous use of graduated compression stockings (GCS). Most trials showing favourable results with the foot pumps have used GCS simultaneously. In theory, the additional use of GCS improves lower limb blood flow and, by controlling the compliance of the calf when the foot pump expels blood, enhances blood flow velocity. However, a duplex ultrasound study showed that the simultaneous use of foot pumps and GCS reduces the peak velocity in the popliteal vein [17]. Apparently, the reduction of pre-load in the foot venous plexus hinders the function of pneumatic compression. Thus, on physiological grounds, GCS should not be used simultaneously with the foot pump. Avoiding the habitually uncomfortable and cumbersome GCS can also simplify postoperative care and could potentially increase patient compliance with foot pumps. Nevertheless, there is no clinical evidence that these assumptions are valid in clinical settings.

The hypothesis of this prospective, comparative study is that in the postoperative management of patients undergoing total hip and knee replacement, foot pumps without the additional use of GCS do not affect the efficacy of DVT prophylaxis, do not increase the risk of side-effects and do improve patient compliance.

\section{Materials and methods}

All patients admitted at one single institution from January 2003 to December 2005 with degenerative osteoarthritis of the hip or knee for THR or TKR management were considered for inclusion in the study. The criteria for exclusion were active malignant tumour, gastrointestinal ulceration, previous bleeding diatheses and superficial wounds or painful joints in the feet.

A-V Impulse System foot-pump units (Orthofix Vascular Novamedix, Andover, UK) were used in all patients. Three orthopaedic surgeons used graduated compression stockings (TED, Kendall, UK) and chemicals (Cartia, aspirin $100 \mathrm{mg}$ ) in combination with the foot pumps. LMWH was used in patients rated to be at high risk for DVT and pulmonary embolism (PE) [15]. Three orthopaedic surgeons used the foot pumps without simultaneous application of antithrombotic stockings; one did not use additional chemical prophylaxis.

All operations were undertaken or directly supervised by experienced orthopaedic surgeons. Spinal anaesthesia was used in all patients. Blood loss was replaced with predonated autologous blood. Perioperative chemical prophylaxis against thromboembolism was not performed. All patients used foot pumps during the hospital stay. The foot-pump slippers were fitted to both feet in the recovery room, and the machine was activated. The nurses were advised to activate the foot pump whenever the patient was not bearing weight. The pneumatic compression cycle was set at 20 /s with a pressure of $130 \mathrm{mmHg}$ applied for $1 \mathrm{~s}$. All patients of the stocking group wore bilateral thigh-high or knee-high antithromboembolic stockings. Physical therapy, range of motion exercises and walking with partial weight-bearing were usually initiated on the second postoperative day. Partial weight-bearing was continued until the 6 th postoperative week in patients with uncemented THR. Patients with cemented THR and TKR started full weight-bearing after healing of the soft-tissues, generally 2 weeks postoperatively. Patients were free to terminate treatment with the foot pump at any time. If foot pump use was discontinued for more than 4 consecutive hours, the patient was excluded from the study, and prophylaxis with chemicals was commenced. At discharge, all patients were managed with graduated compression stockings and aspirin until full weight-bearing was permitted. The primary outcome measure was the incidence of DVT, monitored with regular clinical examinations during the hospital stay and at the 6- 
week follow-up. Patients with clinical signs of DVT were screened in serial bilateral duplex studies performed using 5.0- and 7.5-MHz linear transducers. Detection of a DVT during the hospital stay warranted continuation with footpump management and therapy with LMWH. Low-molecular-weight heparin was also used in the case of onset of DVT after discharge. The secondary outcome measures were those related to adverse side-effects. Swelling and bruising of the thigh and oozing of the wound were assessed and scored using published criteria $[11,16]$. Assessment of softtissue side-effects was not blinded. Postoperative bleeding events were monitored and classified as minor bleeding from a wound, major bleeding from a wound or major bleeding not related to a wound. The third outcome measure was patient compliance with the foot pumps, assessed with an internal meter that recorded the total number of hours that the device was activated. At discharge, patients were asked if they found the treatment with the foot pump painful, comfortable, relaxing or annoying.

\section{Statistical analysis}

With the use of a two-sided $95 \%$ confidence interval, we rated that the comparative study with a sample size of 800 patients would have an $80 \%$ power to detect a $20 \%$ difference in the effectiveness and safety of the two interventions for the prophylaxis of DVT. The continuous demographic data of the two groups of patients were analysed using a two-tailed, unpaired $t$-test. For rank-scaled data, median values were given with the interquartile range. Relative frequencies of unpaired samples were compared using Fisher's exact test. Unpaired groups of continuous data without the assumption of a normal distribution were compared by means of the Mann-Whitney $U$-test. Two-sided $p$ values of $p \leq 0.05$ were considered to be significant. Correction for multiple comparisons was done with the method of Hommel to control type-I error. All calculations were carried out with sPSS for Windows (ver. 9; SPSS, Chicago, Il.).

\section{Results}

A total of 846 consecutive patients with degenerative osteoarthritis of the hip or knee were allocated in the study.
Forty-six patients discontinued the use of foot pumps during their hospital stay, leaving 400 patients who received foot pumps in combination with graduated compression stockings and 400 patients who have been managed with foot pumps without stockings; chemical prophylaxis was not used in 205 of the no-stocking patients.

Table 1 presents the demographic details of the 800 patients. There were no statistically significant differences between the two groups for any of the measures listed. Two patients died during the observation period (one in each group) for reasons unrelated to the surgical procedure.

Eleven patients of the stocking group $(2.7 \%)$ and nine patients of the no-stocking group (2.3\%) developed postoperative symptomatic DVT. The difference was not significant $(p \leq 0.05)$ (Table 2). Eight patients of the stocking group had a distal DVT and three patients had a proximal DVT. Seven patients of the no-stocking group had a distal DVT, and two had a proximal DVT.

Postoperative symptomatic DVT in six of these 11 patients in the stocking group was detected during the hospital stay; in the no-stocking group, the incidence was five of the nine patients. Of the patients that developed DVT, nine $(9 / 20 ; 45 \%)$ manifested the symptoms after discharge. DVT was more frequent in TKR $(10 / 364 ; 2.7 \%)$ than in THR $(10 / 436 ; 2.3 \%)$; the difference, however, was not statistically significant. All patients had DVT detected in the operated extremity. The length of the thrombus averaged $10 \mathrm{~cm}$ (range: 5-22 cm) in the affected patients of the stocking group and $11 \mathrm{~cm}$ (range: $6-21.5 \mathrm{~cm}$ ) in the patients who were managed without stockings. The difference between the groups was not significant. Resolution of the DVT was observed 6 months after onset in all but two patients.

Non-fatal PE occurred in four patients of the 20 with symptomatic DVT - two of the stocking group and two of the no-stocking group. The onset of PE was within the first 6 weeks following the surgical procedure. All patients recovered uneventfully within 1 month after the occurrence of the embolism.

Additional chemical prophylaxis was used in all patients of the stocking group and in 195 patients of the no-stocking group. Postoperative drainage, oozing, bruising and swelling were similar in the two groups of patients (Table 3).

Table 1 Patient demographics

\footnotetext{
${ }^{a}$ Where indicated $( \pm)$, values are given as the mean and the standard deviation.
}

\begin{tabular}{llll}
\hline & $\begin{array}{l}\text { Stocking group } \\
(n=400 \text { patients })\end{array}$ & $\begin{array}{l}\text { No-stocking group } \\
(n=400 \text { patients })\end{array}$ & $\begin{array}{l}\text { Level of } \\
\text { significance }(p)\end{array}$ \\
\hline Gender (M/F) & $1 / 1.2$ & $1 / 1.3$ & 0.8 \\
Age (years) & $67.3 \pm 10$ & $65.1 \pm 9$ & 0.7 \\
Body mass index $\left(\mathrm{kg} / \mathrm{m}^{2}\right)$ & $30.8 \pm 3.7$ & $31.5 \pm 3.2$ & 0.4 \\
Duration of hospital stay (days) & $5 \pm 2.1$ & $5 \pm 2.7$ & 0.6 \\
Affected joint (knee/hip) & $185 / 215$ & $179 / 221$ & 0.6 \\
\hline
\end{tabular}


Table 2 Symptomatic deepvein thrombosis (DVT) detected by duplex ultrasonography

\begin{tabular}{llll}
\hline & $\begin{array}{l}\text { Stockings group } \\
(n=400 \text { patients })\end{array}$ & $\begin{array}{l}\text { No-stocking group } \\
(n=400 \text { patients })\end{array}$ & $\begin{array}{l}\text { Level of } \\
\text { significance }(p)\end{array}$ \\
\hline Total DVT & 11 & 9 & 0.07 \\
Onset at Day 5 & 6 & 4 & 0.20 \\
Onset at Day 10 & 5 & 5 & \\
Onset at Day 45 & - & - & 0.09 \\
Proximal DVT & 3 & 2 & 0.11 \\
Distal DVT & 8 & 7 & \\
DVT involving entire limb & - & - & 0.08 \\
DVT of contra lateral limb & - & - & 0.18 \\
Affected joint (knee/hip) & $6 / 4$ & $4 / 6$ & \\
Resolution of DVT at Day 45 & 10 & 8 & \\
Pulmonary embolism & 2 & 2 & \\
\hline
\end{tabular}

However, the 205 patients of the no-stocking group managed without chemicals had less postoperative drainage, oozing, bruising and swelling than those who had received aspirin or LMWH. One of the 79 patients $(1.3 \%)$ treated with LMWH was observed to develop clinically asymptomatic heparin-induced thrombocytopenia (HIT)syndrome (type 1) on the third postoperative day.

Of the 846 patients, 46 (5.4\%) discontinued intervention with foot pumps between days 2 and 6 (average: 3.2 days) following the surgical procedure. The reason for termination was sleep disturbances in 32 patients and discomfort around the ankle in 14 patients. Symptomatic DVT was detected in one patient of this group $(2.2 \%)$. Compliance for use of foot pumps was higher in the non-stocking group. Of the 400 patients managed without stockings, $16(4 \%)$ discontinued intervention during their hospital stay, while 30 of the 400 patients $(7.5 \%)$ with stockings asked to discontinue foot-pump treatment. The difference is statistically significant $(p \leq 0.05)$. Three patients who had used the foot pump found it to be painful, ten found it uncomfortable, 70 found it annoying and reported some difficulty with sleeping and 505 reported no discomfort. In contrast, 212 patients found that the foot pump was relaxing. The internal compliance meter indicated that the foot pump had been used for a mean of $15.9 \mathrm{~h}$ daily (range: 14-20.5 hours). The daily mean use of the 20 patients who had a symptomatic DVT was $13.1 \mathrm{~h}$. The difference is not statistically significant $(p=0.08)$.

\section{Discussion}

Foot pumps are effective and safe in THR, and in all of the studies published to date, GCS were used simultaneously with the foot pumps $[5,11,13,16]$. Following TKR, the effectiveness of foot pumps is less certain, with some studies reporting a benefit and others not $[3,18]$. In some of these studies GCS were not used. To our knowledge, our

Table 3 Side-effects

\begin{tabular}{llll}
\hline & $\begin{array}{l}\text { Stocking groupa } \\
(\text { chemicals })^{\mathrm{a}} \\
(n=400 \text { patients })\end{array}$ & $\begin{array}{l}\text { No-stocking group } \\
{\text { (chemicals })^{\mathrm{a}}}_{(n=195 \text { patients })}\end{array}$ & $\begin{array}{l}\text { No-stocking group } \\
(\text { no chemicals })^{\mathrm{a}} \\
(n=205 \text { patients })\end{array}$ \\
\hline $\begin{array}{l}\text { Postoperative drainage }(\mathrm{ml}) \\
\text { Swelling of thigh at Day 3 }(\mathrm{mm})\end{array}$ & $570 \pm 40$ & $547 \pm 51$ & $412 \pm 29^{*}$ \\
No bruising at Day 3 (number of joints) & $22.9 \pm 5$ & $21.1 \pm 7$ & $15.2 \pm 5^{*}$ \\
No oozing at Day 3 (number of joints) & 121 & 107 & $155^{*}$ \\
Minor bleeding from the wound & 209 & 12 & $161^{*}$ \\
Major bleeding from the wound $^{\mathrm{c}}$ & 28 & - & $8^{*}$ \\
\hline
\end{tabular}

*Statistically significant $(p \leq 0.05)$

${ }^{a}$ Where indicated $( \pm)$, values are given as the mean and the standard deviation.

${ }^{\mathrm{b}}$ Median of the differences of the thigh circumferences measured after the operation, compared to the preoperative measurement (baseline). Swelling was assessed by measuring the circumference of the thigh $20 \mathrm{~cm}$ proximal to the patella.

${ }^{\mathrm{c}}$ Minor bleeding from the wound: bleeding at the injection site, epistaxis or wound haematoma not requiring operative decompression. Major bleeding from the wound: wound haematoma requiring operative decompression. Major bleeding not related to the wound: gastrointestinal or intracerebral haemorrhage 
study is the first comparative prospective trial performed to establish whether the effect of the foot pumps is enhanced or hindered by the simultaneous use of GCS. The results of this study indicate that, in comparison with a regimen of foot pumps and concomitant GCS post-THR and -TKR, the use of foot pumps alone is not associated with a reduced efficacy of DVT prevention, is safe and promotes improved patient compliance.

The potential lack of side-effects with pneumatic compression with foot pumps has been regarded as a major advantage. In our study patients of the no-stocking group were managed without chemicals and showed a significant reduction in wound drainage, minor wound bleeding, bruising and oozing of the wound, and swelling of the thigh, when compared to patients managed without stockings and with chemicals. This confirms findings of other randomised studies and shows that the use of stockings does not affect rates of side-effects.

Compliance and tolerance have been reported to be a problem with the use of pneumatic compression systems [3, 12]. Pitto et al. reported a termination rate of $13.8 \%(16 / 116$ patients) [11]. The main reason for discontinuation was sleep disturbance at night due to the noise produced by the device. Warwick et al. reported a discontinuation rate of $3 \%$ in patients who wore the foot pumps for an average of $15 \mathrm{~h}$ daily for 7 days [16]. In both studies, GCS were used in all patients. In our study, the discontinuation rate of patients treated with stockings was $7.5 \%$; in contrast, only $4 \%$ of patients without stockings terminated the intervention with foot pumps. The average use of the foot pumps was $15.9 \mathrm{~h}$ for 5 days. Generally speaking, the acceptance of foot pumps by patients and nursing staff in the ward was also improved when used without GCS. In fact, avoiding GCS management facilitates postoperative nursing care and increases overall patient comfort.

This study has some limitations. Firstly, the use of foot pumps with or without stockings was not randomised. Nevertheless, the two groups of patients were reasonably homogeneous, and demographic differences were not statistically significant. Secondly, additional chemical prophylaxis was not used in approximately one half of the patients of the intervention group managed without stockings. This factor may have influenced the outcome of the study. Aspirin was the most commonly used prophylactic chemical in the study. The efficacy of aspirin for prevention of DVT after THR and TKR is unclear. A large multicentre, randomised study showed that aspirin does not significantly affect the rate of DVT and PE after joint replacement procedures [9]. Another randomised clinical trial showed that the prevalence of DVT following TKR was $27 \%$ in the group treated with pneumatic plantar compression and aspirin and $59 \%$ in the patients managed with aspirin alone [18]. Therefore, we assume that the low rate of DVT and limited side-effects observed in the present study were mainly related to the use of the foot pumps. We did not perform duplex ultrasonography screening for DVT in all patients, only in those with symptoms suggesting postoperative DVT. This explains the low rates of DVT observed in the two groups of patients. We assume that a routine duplex ultrasonography would have detected a number of non-symptomatic venous thrombi, otherwise not identified with clinical examination [8].

In conclusion, the management of patients with foot pumps but without GCS does not reduce the efficacy of DVT prophylaxis following THR and TKR. Patient compliance in using the foot pumps improves when the use of GCS can be avoided.

\section{References}

1. Andrews BT, Sommerville K, Wilson N, Browse NL (1993) The effect of foot compression on the velocity and volume of blood flow in the deep veins. J Bone Jnt Surg Br 80:198-200

2. Borghi B, Casati A; Rizzoli Study Group on Orthopaedic Anaesthesia (2002) Thromboembolic complications after total hip replacement. Int Orthop 26:44-47

3. Charalambous C, Cleanthous S, Tryfonidis M, Goel A, Swindell R, Ellis D (2003) Foot pump prophylaxis for deep venous thrombosis-rate of effective usage following knee and hip arthroplasty. Int Orthop 27:208-210

4. Fleming P, Fitzgerald P, Devitt A (2000) The effect of position of the limb on venous impulse foot pumps. J Bone Jnt Surg Br $82: 433-435$

5. Fordyce MJF, Ling RSM (1992) A venous foot pump reduces thrombosis after total hip replacement. J Bone Jnt Surg Br 74: 45-49

6. International Consensus Statement Group (2001) Int Angiol 20: $1-37$

7. Kim YH, Choi IY, Park MR, Park TS, Cho JL (1998) Prophylaxis for deep vein thrombosis with aspirin or low molecular weight dextran in Korean patients undergoing total hip replacement. A randomized controlled trial. Int Orthop 22:6-10

8. Ko PS, Chan WF, Siu TH, Cheng A, Lee OB, Lam JJ (2003) Duplex ultrasonography after total hip or knee arthroplasty. Int Orthop 27:168-171

9. Pulmonary Embolism Prevention (PEP) study Group (2000) Prevention of pulmonary embolism and deep vein thrombosis with low dose aspirin trial. Lancet 355:1288-1289

10. Pitto RP, Kuehle J, Hamer H, Radespiel-Troger M, Pietsch M (2001) Hemodynamics of the lower extremity with pneumatic foot compression. Effect on leg position. Biomed Tech 46: 124-128

11. Pitto RP, Hamer H, Heiss-Dunlop W, Kuehle J (2004) Mechanical prophylaxis of deep-vein thrombosis after total hip replacement. A randomized clinical trial. J Bone Jnt Surg Br 86:639-642

12. Robertson KA, Bertot AJ, Wolfe MW, Barrack RL (2000) Patient compliance and satisfaction with mechanical devices for preventing deep venous thrombosis after joint replacement. J South Orthop Assoc 9:182-186

13. Santori FS, Vitullo A, Stopponi M, Santori N, Ghera S (1994) Prophylaxis against deep-vein thrombosis in total hip replacement. Comparison of heparin and foot impulse pump. J Bone Jnt Surg $\operatorname{Br} 76: 579-583$ 
14. Stone MH, Limb D, Campbell P, Stead D, Culleton G (1996) A comparison of intermittent calf compression and enoxaparin for thromboprophylaxis in total hip replacement. A pilot study. Int Orthop 20:367-369

15. Thomas DP (2000) Whither thromboprophylaxis after total hip replacement? J Bone Jnt Surg Br 82:469-472

16. Warwick D, Harrison J, Glew D (1998) Comparison of the use of a foot pump with the use of low-molecular-weight heparin for the prevention of deep-vein thrombosis after total hip replacement. A prospective, randomized trial. J Bone Jnt Surg Am 80:1158-1166
17. Warwick DJ, Pandit Hermant, Shewale S, Sulkin T (2002) Venous impulse foot pumps. Should graduated compression stockings be used? J Arthoplasty 17:446-448

18. Westrich GH, Sculco TP (1996) Prophylaxis against deep venous thrombosis after total knee arthroplasty. Pneumatic plantar compression and aspirin compared with aspirin alone. J Bone Jnt Surg Am 78:826-834

19. Westrich GH, Haas SB, Mosca P, Peterson M (2000) Metaanalysis of thromboembolic prophylaxis after total knee arthroplasty. J Bone Jnt Surg Br 82:795-800 